\title{
Life tables for the common dormouse Muscardinus avellanarius in Lithuania
}

\author{
Rimvydas JUŠKAITIS
}

\begin{abstract}
Juškaitis R. 1999. Life tables for the common dormouse Muscardinus avellanarius in Lithuania. Acta Theriologica 44: 465-470.

Life tables for two populations of the common dormouse Muscardinus avellanarius (Linnaeus, 1758) are presented. The mortality rates $q_{x}$ of the common dormouse appeared to be relatively constant and did not follow a typically mammalian "U" shaped curve with age. Mortality rates increased evenly with age both in females and males, in both populations, whereas a decrease in $q_{x}$ was observed only among males in their third year of life. Specific characteristics of the $q_{x}$ curve for the common dormouse include the relative longevity of this small rodent, and rather constant mortality during hibernation in all years of life.
\end{abstract}

Institute of Ecology, Akademijos 2,LT-2600 Vilnius, Lithuania, e-mail: juskaitis@takas.lt Key words: Muscardinus avellanarius, life table, mortality rate, Lithuania

\section{Introduction}

The mortality pattern in animal populations is usually presented as a life table (Caughley 1966, 1977, Fleming 1979, Schwerdfeger 1979, Flowerdew 1987, Johnson 1994 etc). Collection of data for mammal life tables is usually tedious and expensive. Consequently, life tables have been made for only a small number of mammal species (Purvis and Harvey 1995, Sibly et al. 1997). None have been made for any species of dormice until now.

Investigations of the structure and dynamics of two isolated common dormouse Muscardinus avellanarius (Linnaeus, 1758) populations carried out in Lithuania between 1984 and 1993 (Juškaitis 1994) enabled data to be collected for the life tables of the common dormouse. These life tables are presented in this paper, and dormouse mortality patterns are analyzed in the two populations, among females and males, and among dormice born in different years.

\section{Material and methods}

Data for the life tables of the common dormouse were collected at site A (Šakiai district, southwest Lithuania), 1983-1990, and at site B (Moletai district, east Lithuania), 1984-1993. Site A with 262 nestboxes occupied a mixed forest area of 60 ha; site B with 341 nestboxes -85 ha. For the descriptions of the study sites see earlier publications (Juškaitis 1994, 1995, 1997). The methods used for the study 
of common dormice were based on three main principles: (1) even spacing of nestboxes in a grid system in large forest area, (2) regular checking of nestboxes, (3) marking of all dormice caught.

At both sites, standard wooden nestboxes for small hole nesting birds were placed every $50 \mathrm{~m}$, at a height of 1.5-2.0 m. The density was four nestboxes in 1 ha. The boxes were checked once a month from April until October, and twice a month in May and September. All dormice caught were marked with aluminum rings (the straightened plate was $2.5 \times 8.0 \mathrm{~mm}$ ). The rings were placed on the right hind leg over a heel. Suckling young weighing less than $10 \mathrm{~g}$ were marked by toe amputation, and ringed when caught again subsequently.

Only data from juveniles born in the same year and marked in August-October in litters, or living independently, were used for calculating life tables. In total 329 dormice (188 males and 141 females) and 739 dormice ( 410 males and 329 females) were used for this aim at site A and at site B respectively. It was assumed that all these juveniles were born at the same time. Dead litters found in nestboxes were also included ( 3 litters with 13 juveniles at site A and 8 litters with 38 juveniles at site B). Marked dormice were checked again after hibernation every year. The dormice that survived one winter were referred to as one-year-olds, those that survived two winters, two-year-olds, etc. Thus the number of still surviving dormice $f_{x}$ was established directly, and later the survival $l_{x}$, mortality $d_{x}$, mortality rate $q_{x}$ and survival rate $p_{x}$ (Caughley 1977) were calculated.

Mortality rate $q_{x}$ - the proportion of animals alive at age $x$ that die before age $x+1$ - was used for the analysis of age-dependent mortality. According to Caughley (1977), $q_{x}$ is least affected by sampling bias, gives the most direct projection of the mortality pattern, and is the best schedule for comparisons within and between species. Mortality rate $q_{x}$ was calculated directly by the formula $q_{x}=\left(f_{x}-f_{x+1}\right) / f_{x}$ (Caughley 1966). Life expectancy at birth $e_{0}$ was calculated by the formula $e_{0}=\Sigma l_{x}-1 / 2$ (Caughley 1966).

As nearly all three-year-old dormice died in the fourth year of their life, the mortality pattern of dormice was analyzed only in the first four years of life.

\section{Results and discussion}

The pattern of changing common dormice mortality with age is presented in the form of life tables (Table 1 and 2). Analysis of these life tables shows that characteristic features for common dormice were rather high mortality in all years of their life, little change in mortality rates with age, and differences between male and female mortality rates which appeared in the third year of life.

Caughley $(1966,1977)$ summarized the existing information on mortality patterns in mammals, concluding that mortality rates typically follow a "U" shaped trend with age. Each $q_{x}$ curve can be divided into two components: a juvenile phase, when the rate of mortality is initially high but rapidly decreases, is followed by a postjuvenile phase characterized by initially low but steadily increasing rate of mortality.

However, the pattern of changing mortality rate $q_{x}$ with age in common dormice had a different character, as shown in Fig. 1, where part of the data from Tables 1 and 2 are presented in a graphic form. The mortality rates of this species appeared to be more constant than usual in mammals. Whereas the mortality rate $q_{x}$ of other mammals decreases considerably in the postjuvenile phase (Caughley 1966), the mortality rate $q_{x}$ of common dormice in the second year remained the same as in the first year. Differences between the sexes were found in the third year in both populations: the mortality rate $q_{x}$ of females increased further, while the mortality 
Table 2. Life table for common dormouse at site B (juveniles born 1984-1990).

\begin{tabular}{|c|c|c|c|c|c|}
\hline Age $(x)$ & Frequency $\left(f_{x}\right)$ & Survival $\left(l_{x}\right)$ & Mortality $\left(d_{x}\right)$ & Mortality rate $\left(q_{x}\right)$ & Survival rate $\left(p_{x}\right)$ \\
\hline \multicolumn{6}{|c|}{ Males } \\
\hline 0 & 410 & 1.000 & 0.793 & 0.793 & 0.207 \\
\hline 1 & 85 & 0.207 & 0.166 & 0.800 & 0.200 \\
\hline 2 & 17 & 0.041 & 0.024 & 0.588 & 0.412 \\
\hline 3 & 7 & 0.017 & 0.012 & 0.714 & 0.286 \\
\hline 4 & 2 & 0.005 & 0.003 & 0.500 & 0.500 \\
\hline 5 & 1 & 0.002 & 0 & 0 & 1.000 \\
\hline 6 & 1 & 0.002 & 0.003 & 1.000 & 0 \\
\hline \multicolumn{6}{|c|}{ Females } \\
\hline 0 & 329 & 1.000 & 0.778 & 0.778 & 0.222 \\
\hline 1 & 73 & 0.222 & 0.170 & 0.767 & 0.233 \\
\hline 2 & 17 & 0.052 & 0.043 & 0.824 & 0.176 \\
\hline 3 & 3 & 0.009 & 0.009 & 1.000 & 0 \\
\hline 4 & 0 & & & & \\
\hline \multicolumn{6}{|c|}{ Males + females } \\
\hline 0 & 739 & 1.000 & 0.788 & 0.788 & 0.212 \\
\hline 1 & 157 & 0.212 & 0.166 & 0.783 & 0.217 \\
\hline 2 & 34 & 0.046 & 0.032 & 0.706 & 0.294 \\
\hline 3 & 10 & 0.014 & 0.011 & 0.800 & 0.200 \\
\hline 4 & 2 & 0.003 & 0.002 & 0.500 & 0.500 \\
\hline 5 & 1 & 0.001 & 0 & 0 & 1 \\
\hline 6 & 1 & 0.001 & 0.001 & 1.000 & 0 \\
\hline
\end{tabular}

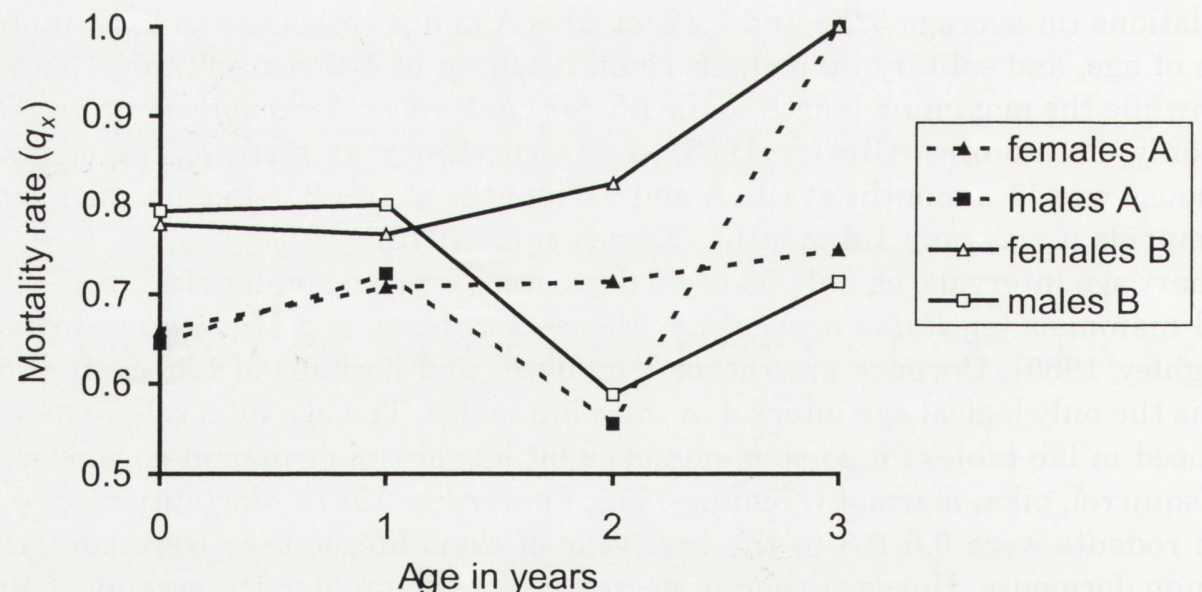

Fig. 1. Changing mortality rate $q_{x}$ with age in common dormice female and male of two populations. 
It is difficult to estimate the mortality of common dormice in the juvenile phase. This problem exists for many mammal species (Caughley 1966, Flowerdew 1987). The mortality of common dormice was likely to be a little higher in the first year than our results showed. Some juveniles could die being unmarked. The young dormice marked in June-July and not recaptured in August-October were not included in the life tables because the young of earlier litters traveled rather long distances. Maximum distances travelled from the birth place by young born in May-July were 800-1200 m, mean distance being 360 30 m (Juškaitis 1997). Most probably these young simply left the areas of investigation but did not die. There are examples corroborating this supposition. In autumn the young traveled comparatively short distances: early born young became sedentary, and maximum distances travelled from the birth place by the young born in August-September were 400-600 m, mean distance being $130 \pm 10 \mathrm{~m}$. In the second year of their life all dormice were sedentary in their home ranges (Juškaitis 1997).

There were differences in the mortality rates $q_{x}$ of dormice born in different years (Table 3 ). For instance, the dormice born in 1986 at site $\mathrm{A}$ had a low $q_{x}$ in all years of their life, affecting the demographic structure of the population (an increase in the proportion of two-year-olds in 1988 and three-year-olds in 1989 was observed). The dormice born in 1984 and 1986 at site B had a rather high $q_{x}$ and short life span. The character of $q_{x}$ curves varied a little between years: decreases in mortality rate $q_{x}$ were observed in some cases in the third year of life, as was

Table 3. Mortality rate $q_{x}$ for common dormice born in different years (males and females pooled). For evidence $q_{x}$ values exceeding 0.7 are printed in bold face, $q_{x}$ values exceeding 0.8 are printed in bold face and underlines.

\begin{tabular}{|c|c|c|c|c|c|c|c|c|}
\hline Age & 1984 & 1985 & 1986 & 1987 & 1988 & 1989 & 1990 & Mean \\
\hline & & & & Site B & & & & \\
\hline 0 & 0.752 & 0.759 & $\underline{0.823}$ & 0.680 & 0.793 & 0.795 & $\underline{0.835}$ & 0.788 \\
\hline 1 & $\underline{0.920}$ & 0.788 & 0.750 & 0.625 & $\underline{0.833}$ & 0.692 & 0.733 & 0.783 \\
\hline 2 & $\overline{1}$ & 0.429 & 0.400 & 1 & $\overline{0.800}$ & 0.750 & 1 & 0.706 \\
\hline 3 & & 0.750 & 0.667 & & 1 & 1 & & 0.800 \\
\hline 4 & & 1 & 0 & & & & & 0.500 \\
\hline 5 & & & 0 & & & & & 0 \\
\hline 6 & & & 1 & & & & & 1 \\
\hline \multirow[t]{2}{*}{$\mathrm{f}_{0}$} & 101 & 137 & 113 & 25 & 145 & 127 & 91 & 739 \\
\hline & & & & Site A & & & & \\
\hline 0 & 0.647 & 0.610 & 0.611 & 0.756 & & & & 0.657 \\
\hline 1 & 0.722 & 0.733 & 0.679 & 0.739 & & & & 0.717 \\
\hline 2 & 0.600 & 0.500 & 0.667 & 0.800 & & & & 0.625 \\
\hline 3 & 1 & 1 & 0.667 & 1 & & & & $\underline{0.917}$ \\
\hline 4 & & & 1 & & & & & 1 \\
\hline $\mathrm{f}_{0}$ & 102 & 77 & 72 & 78 & & & & 329 \\
\hline
\end{tabular}


characteristic of males. One difference between the two populations investigated came to light. At site B mortality rate $q_{x}$ was higher both in males and females in almost all cases, however the reasons of this difference were not yet clear.

The longevity of common dormice in comparison to other small mammals of similar body size, rather constant mortality during hibernation in all years of their life and age interval of one year in their life tables defines a characteristic $q_{x}$ curve for this species.

Acknowledgements: I am very grateful to Prof P. A. Morris and anonymous reviewers for critical remarks concerning the earlier versions of the manuscript and for the revision of the English text.

\section{References}

Caughley G. 1966. Mortality patterns in mammals. Ecology 47: 906-918.

Caughley G. 1977. Analysis of vertebrate populations. John Wiley \& Sons, London, New York, Sydney, Toronto: 1-234.

Fleming T. H. 1979. Life-history strategies. [In: Ecology of small mammals. D. M. Stoddart, ed]. Chapman and Hall, London: 1-61.

Flowerdew J. R. 1987. Mammals. Their reproductive biology and population ecology. Arnold, London: $1-241$.

French N. R., Stoddart D. M. and Bobek B. 1975. Patterns of demography in small mammal populations. [In: Small mammals: their productivity and population dynamics. F. B. Golley, K. Petrusewicz and L. Ryszkowski, eds.]. Cambridge University Press, Cambridge: 73-102.

Gliwicz J. 1983. Survival and life span. [In: Ecology of the bank vole. K. Petrusewicz, ed]. Acta Theriologica 28, Suppl. 1: 66-75.

Johnson D. H. 1994. Population analysis. [In: Research and management techniques for wildlife and habitats. T. A. Bookhout, ed]. The Wildlife Society Bethesda, Maryland: 419-444.

Juškaitis R. 1994. The structure and dynamics of common dormouse (Muscardinus avellanarius L.) populations in Lithuania. Proceedings of II Conference on Dormice. Hystrix (n. s.) 6: 273-279.

Juškaitis R. 1995. Relations between common dormice (Muscardinus avellanarius) and other occupants of bird nest-boxes in Lithuania. Folia Zoologica 44: 28-35.

Juškaitis R. 1997. Ranging and movement of the common dormouse Muscardinus avellanarius in Lithuania. Acta Theriologica 42: 113-122.

Purvis A. and Harvey P. H. 1995. Mammal life-history evolution: a comparative test of Charnov's model. Journal of Zoology, London 237: 259-283.

Schwerdtfeger F. 1979. Ökologie der Tiere. Bd. 2. Demökologie: Strukture and Dynamik tierischen Populationen. 2 neubearb. Aufl. Verlag Paul Parey. Hamburg und Berlin: 1-452.

Sibly R. M., Collett D., Promislow D. E. L., Peacock D. J. and Harvey P. H. 1997. Mortality rates of mammals. Journal of Zoology, London 243: 1-12.

Received 17 March 1998, accepted 15 April 1999. 